\title{
Social constructivism in mathematics? The promise and shortcomings of Julian Cole's institutional account
}

\author{
Jenni Rytilä ${ }^{1}$
}

Received: 12 February 2021 / Accepted: 2 July 2021 / Published online: 18 July 2021

(c) The Author(s) 2021

\begin{abstract}
The core idea of social constructivism in mathematics is that mathematical entities are social constructs that exist in virtue of social practices, similar to more familiar social entities like institutions and money. Julian C. Cole has presented an institutional version of social constructivism about mathematics based on John Searle's theory of the construction of the social reality. In this paper, I consider what merits social constructivism has and examine how well Cole's institutional account meets the challenge of accounting for the characteristic features of mathematics, especially objectivity and applicability. I propose that in general social constructivism shows promise as an ontology of mathematics, because the view can agree with mathematical practice and it offers a way of understanding how mathematical entities can be real without conflicting with a scientific picture of reality. However, I argue that Cole's specific theory does not provide an adequate social constructivist account of mathematics. His institutional account fails to sufficiently explain the objectivity and applicability of mathematics, because the explanations are weakened and limited by the three-level theoretical model underlying Cole's account of the construction of mathematical reality and by the use of the Searlean institutional framework. The shortcomings of Cole's theory give reason to suspect that the Searlean framework is not an optimal way to defend the view that mathematical reality is socially constructed.
\end{abstract}

Keywords Social constructivism · Mathematical entities · Julian C. Cole · Ontology of mathematics $\cdot$ Social ontology $\cdot$ John Searle

Jenni Rytilä

jenni.rytila@tuni.fi

1 Tampere University, Tampere, Finland 


\section{Introduction}

One central question in the philosophy of mathematics is the question of the nature of mathematical objects and their existence. To illustrate with an example, let's define two numbers: let $n$ be the largest prime number smaller than $10^{10^{10}}$, and let $m$ be the largest prime number. As anyone familiar with ordinary mathematics may tell you, there is a clear difference between these two numbers: $n$ exists, but $m$ does not. This may be enough said on the matter for a working mathematician, but if she is in a philosophical mood, some questions may arise: Does $n$ really exist? Obviously, it does not exist in the same way as the paper it is written on. On the other hand, if $n$ does not exist at all, why does it differ from $m$ in the sense mentioned above? From considering the specific example, she may be led to ponder a more general question: What kinds of entities are the things talked about in mathematics?

In this paper, I consider a view that answers this question differently than traditional philosophical views of mathematics, namely, I consider mathematical social constructivism as a metaphysical theory about what mathematical reality is like. ${ }^{1}$ The core idea of social constructivism is that mathematical entities are social constructs that exist in virtue of social practices, similar to more familiar social entities like institutions, money, and the like. I examine one form of social constructivism in detail: Cole's $(2013,2015)$ institutional theory of the social construction of mathematical reality. ${ }^{2}$ Cole bases his account on John Searle's theory of social construction and defends the view that mathematical reality is a product of imposing function onto reality and that its existence depends on collective recognition. My aim in this paper is to consider what merits social constructivism has and to examine how well the institutional account meets the challenges facing social constructivist accounts of mathematics.

I begin in section two by exploring some differences between social constructivism about mathematics and constructive mathematics in order to clear up possible confusion arising from using the term 'constructivism'. In section three, I explore how mathematical practice motivates a social constructivist view of mathematics and describe the details of Cole's institutional theory. I also examine in what way Cole's social constructivism is a realist view. In section four, I consider some merits of mathematical social constructivism and present a new argument in favor of the view. The success of the argument depends on the ability of the social constructivist view to account for the characteristic features of mathematics. In section five, I identify two particular features that present a significant challenge for social constructivism-objectivity and applicability—and examine how well Cole's institutional theory accounts for them. I argue that Cole's theory fails to sufficiently explain the objectivity and applicability of mathematics because the explanations are weakened

\footnotetext{
${ }^{1}$ Mathematical reality can consist of either objects or structures, but I will here leave this ambiguous and talk about entities, using it as an inclusive term. Cole uses the similarly inclusive term 'facet of reality'.

${ }^{2}$ Other prominent proponents of social constructivism about mathematics are Ernest (1998) and Hersh (1997).
} 
and limited by the three-level theoretical model underlying Cole's account of the construction of mathematical reality and by the Searlean framework he uses. To conclude, I suggest that the institutional social ontology Cole uses is not an optimal way to defend the view that mathematical reality is socially constructed.

\section{How mathematical social constructivism differs from constructive mathematics}

Despite sharing the name constructivism, mathematical social constructivism differs in significant ways from the more familiar constructivism in mathematics, namely, constructive mathematics. Constructive mathematics is characterized by a strict requirement of constructability and provability. The statement "there is $x$ " is interpreted in constructive mathematics as "we can construct $x$," and the statement " $p$ is true" as "we can give a proof for $p$." These requirements have far-reaching implications for the methodology of mathematics: the law of excluded middle does not hold in constructive mathematics, and instead of classical logic, intuitionistic logic is used. (See Bridges \& Palmgren, 2018).

There are different forms of constructive mathematics, from constructive recursive mathematics to constructive type theory, but philosophically, the most influential version is L.E.J. Brouwer's intuitionism. Brouwer sees mathematical entities as languageless mental creations arising from the perception of the passage of time. The basic intuition of mathematics is the distinctness of two moments, which creates natural numbers when repeated indefinitely. Brouwer understood the truth of a mathematical statement as having a mental construction of the statement's proof. Brouwer's intuitionism is an attempt to provide an epistemological and ontological foundation for mathematics in the form of mental constructions. (Iemhoff, 2019). Here we find the first difference: social constructivism does not aim to give a foundation to mathematics but rather explicates the nature of mathematical existence from a wider ontological perspective.

The second and main difference between social constructivism and constructive mathematics is in their relation to mathematical practice. Constructive mathematics is fundamentally a view about how mathematics should be practiced; it states how logical connectives should be interpreted, what methods of proof are permissible, and which principles are acceptable. In contrast, mathematical social constructivism does not pose restrictions on how mathematicians should do mathematics, what entities are permissible, or how mathematical entities should be defined while proving theorems. Cole (2015, p. 1103) argues that social constructivism is neutral concerning the dispute between constructive and classical mathematics. What this neutrality amounts to can be specified by making the distinction between different aspects of constructive mathematics: Brouwerian ontological constructivism, which asserts that mathematical entities are mental constructs, and epistemological constructivism, which is a view about the proper methodology of mathematics, namely intuitionistic logic (Bridges \& Palmgren, 2018). Social constructivism is neutral concerning epistemological constructivism; it is compatible with constructive as well as with classical methodology. But since social constructivism is a metaphysical thesis 
about the nature of mathematical reality, it is evidently not ontologically neutral. However, it should be noted that social constructivism makes a claim about the metaphysical nature of mathematical entities but does not take a stand on which entities exist. Because of the permissiveness regarding methodologies, social constructivism allows for different ontological inventories of mathematical reality. For example, a social constructivist who works with intuitionistic methods might agree with Brouwer's intuitionistic ontology about what entities there are but disagree about what they are like metaphysically. In this latter sense, social constructivism is a rival for Brouwerian ontological constructivism.

Although social constructivism and ontological constructivism share the idea of mathematical entities being constructions, the kind of constructing in social constructivism is different from the explicit construction required by constructive mathematics. Regardless of what does the constructing-whether it is the mind of an individual mathematician or an algorithm ${ }^{3}$ - the construction in constructive mathematics is done within the theory. In social constructivism, it functions on another level. The idea is that entities postulated in mathematical theories depend on practices for their existence, but they need not be explicitly defined in the theory. Thus, the third difference is that instead of the concrete construction of objects in constructive mathematics, mathematical entities in social constructivism are constructed in the sense that they are intended or unintended products of mathematical social practices (see Haslanger, 1995, p. 97).

\section{Julian Cole's institutional account of mathematics}

\subsection{Motivation from the ontological puzzle}

Motivation for accepting social constructivism about mathematics comes from the practice of doing mathematics. Cole (2009) describes a puzzle arising from mathematical practice, which points toward the need for a new metaphysical interpretation of mathematics. On the one hand, mathematicians frequently make existential statements and refer to mathematical entities. There is also a clear sense of discovery in the experience of studying mathematics; mathematical entities seem to have objective features we can determine and by which we can even be surprised. On the other hand, new mathematical entities are freely postulated in the course of solving problems. Postulation is a creative act, constrained only by the needs of the problem to be solved and the requirement of coherency.

Cole (2009) notes that mathematicians have the authority to both make ontological commitments to existing entities and freely and creatively postulate new entities. These are legitimate practices of working mathematicians that should not be questioned from an outside perspective. The trouble is that our traditional metaphysical

\footnotetext{
3 According to Brouwer, mathematical objects are constructed in the mind of an individual mathematician-or the Creating Subject as an idealized mind (Iemhoff, 2019). In modern computational interpretations of constructive mathematics, objects are constructed by algorithms (Bridges \& Palmgren, 2018).
} 
interpretations of mathematics do not manage to adequately account for both aspects of mathematical practice.

If taken seriously, the ontological commitments made in the practice of mathematics point toward a platonist (or robustly realist) ontology. ${ }^{4}$ But, as Cole (2009) argues, the freedom to creatively postulate new entities runs into problems with a platonist ontology. From the perspective of the working mathematician, "postulation is guided by the problem to be solved and a need for coherence" (Cole, 2009, p. 591). However, in a platonist interpretation of mathematical theories, the postulated entities should capture a mathematical reality that exists entirely independently of the mathematical activities. This places further constraints on mathematical innovation and curtails mathematicians' freedom. ${ }^{5}$ It would also be "an unnerving happenstance" if the postulated entities were to correspond to those existing in the Platonic realm (Cole, 2009, p. 591), because, due to the challenges of gaining epistemological access ${ }^{6}$ to it, it is difficult to see how postulation could be guided by the Platonic realm.

The practice of creatively postulating new entities agrees well with fictionalism and other nominalist ontologies as well as with intuitionistic ontology. Creating new entities is not a problem if the entities in question are not real or if they are considered to be nothing but mental creations in the first place. But these metaphysical alternatives invalidate the ontological commitments made in the practice of mathematics and fail to account for the sense of discovery in mathematics.

Yet another option is to look for the subject matter of mathematics in the natural world, but empiricism runs into trouble with both aspects of practice. The natural world is not vast enough to substantiate all the ontological commitments made in modern mathematics, and limiting the subject matter of mathematics to the features of the physical world would significantly restrict the possibility of creative postulation.

The puzzle that Cole presents is this:

The freedom and authority that mathematicians feel they enjoy to creatively postulate mathematical entities do not accord well with realist or Platonist interpretations of mathematical theories. Yet, the intellectual ease with which mathematicians ontologically commit themselves to mathematical entities does not accord well with fictionalist or modal nominalist interpretations of mathematical theories. (Cole, 2009, p. 593; emphasis in original)

\footnotetext{
4 In this paper, I use 'platonism' to cover a range of metaphysical views that see mathematical entities as non-spatiotemporal, acausal entities existing entirely independently of mathematical activities; in addition to realism about objects such as numbers, these views include versions of set-theoretic realism and ante-rem structuralism. Maddy (2011) calls this type of view Robust Realism.

${ }^{5}$ Unless we are willing to accept an extremely large universe of mathematical entities, with possibly multiple different and conflicting universes of sets to ensure that whatever we postulate corresponds to a pre-existing entity. An example of this kind of view is the full-blooded platonism of Balaguer (1995).

6 This is the much-discussed Benacerraf-Field epistemological challenge. See, e.g., Nutting (2020) for a clear formulation of the arguments.
} 
According to Cole (2009, p. 607), the only plausible solution to this puzzle is a metaphysical view that sees mathematical entities as real but dependent on practices. Cole $(2008,2009)$ calls his position practice-dependent realism. Practice-dependent, because mathematical facets of reality depend on practices for their existence; without humans and their practices of counting, calculating, formulating theories, and proving theorems, there would be no mathematical objects. Realism, because despite their dependence on practices, the objects and structures studied in mathematics are taken to genuinely exist and to have objective features (Cole, 2008, p. 121, 2009, p. 600).

The point is to say that mathematical facets of reality are real in the same way that universities and money and other familiar parts of social reality are real; they are not independent of human activity but are genuine aspects of reality nevertheless. ${ }^{7}$ I see this as the core idea of mathematical social constructivism. But we need a detailed account to explain exactly how mathematical reality depends on practices. How can something real come into being just by us humans acting in certain ways? Further, how can the results be as objective as mathematics is taken to be?

Cole $(2013,2015)$ gives such an account, which is based on John Searle's theory of the construction of social reality. Before going into the details of Cole's account of mathematics, I present a brief overview of Searle's theory.

\subsection{Searle's theory of how social reality is constructed}

According to Searle's $(1995,2010)$ theory, the basis of social reality is the ability to impose functions on objects and people. Some functions are based on physical features; for example, a stump of a tree can be given the function of a chair because its physical features make it suitable for sitting. But there are other functions that objects and people can perform that have little to do with physical features and are instead based on a collectively recognized status; these are called status functions (Searle, 2010, p. 7). A piece of paper can perform the function of money only in virtue of having a status as, say, a 10-euro bill. Status functions carry deontic powers: rights, responsibilities, duties, permissions, obligations, and so on (Searle, 2010, pp. 8-9). Because the piece of paper has the status function of money, I have the right to exchange the bill for a meal in a restaurant.

Status functions are imposed differently than physical functions, such as functioning as a chair. Imposing a physical function onto reality typically requires causally manipulating the environment in some way, such as sawing a tree stump to make it level and suitable for sitting, but imposing a status function requires merely collectively recognizing and representing the relevant object or person as having a certain status. According to Searle (2010, p. 13), status functions are created by making "Status Function Declarations," which are collective representational acts that have the same logical form as a certain type of speech acts called declarations. The central feature of declarations is their ability to bring a state of affairs into existence just

\footnotetext{
7 It should be noted that a position like this requires a realist attitude regarding social entities in general. I discuss the issue of realism more in Sect. 3.5.
} 
by declaring that the state of affairs exists (Searle, 2010, p. 12). Paradigm examples of declarations include "I pronounce you married" and "I appoint you chairperson"; a marriage is formed, and an individual becomes the chairperson just by saying these words in the right conditions. Status functions are created similarly; for example, in a card game, a joker gets the status of a missing card if the players declare, "this is now the queen of diamonds," and recognize it as such with the appropriate deontic powers.

The rest of the cards also have status functions without the players needing to create them by constantly declaring the values of the cards during play. Searle's explanation for this is that some status function declarations remain in force for an extended period of time. Searle (2010, p. 13) calls these standing declarations and equates them with constitutive rules of the form " $X$ counts as $Y$ in context $C$." Constitutive rules are those that not only regulate a certain activity but also create the possibility of the activity in the first place. For example, the rules of chess are constitutive of the game because without following the rules, the activity of moving black and white pieces on a board would not be a game of chess (Searle, 1995, pp. 27-28). The constitutive rule " $X$ counts as $Y$ in context $C$ " can be thought of as an implicit and continuing declaration that a status function $Y$ exists: the piece of paper in my wallet keeps being money because of the constitutive rules regarding euros. Alternatively, constitutive rules can be thought of as creating the conditions for the creation of status functions in specific cases: the constitutive rule of checkmates in chess does not create checkmates but rather makes it the case that in a specific game of chess, moving the bishop to a certain square can count as checkmate. (Searle is not entirely clear on this matter; see Tsohatzidis, 2010). Either way, systems of constitutive rules or standing declarations are crucial for the continuing existence of status functions. For Searle (2010, p. 10), a human institution is a system of constitutive rules, and so, Searle calls institutional all parts of reality that depend on constitutive rules for their existence: money, corporations, marriages, card games, and other aspects of social reality.

To sum up, Searle's (2010) central claim is that all institutional reality is created and maintained in existence by the mechanism of status function declarations and collective recognition. The idea of Cole's mathematical social constructivism is that mathematical reality is part of institutional reality and is constructed in a similar way; mathematical objects and domains are products of systems of standing declarations, and they maintain their existence by collective recognition (Cole, 2015, p. 1111).

\subsection{Surrogate objects}

Cole adds to Searle's theory a third kind of function that we impose onto reality, which he calls surrogacy functions (Cole, 2015) or representational functions (Cole, 2013). Surrogacy functions are imposed onto reality to aid in representational activities like inquiring, reasoning, finding truths, etc. These activities become easier when their subject matter is treated as an object with properties and relations. Thus, as Cole (2015, p. 1110) says, "when the subject matter of certain representational 
activities is not standardly treated as an object in our representations, we frequently engage in those activities using an alternative system of representation in which it is treated as an object." Cole calls these surrogate objects.

One example of a surrogate object given by Cole (2015, p. 1109, 2013, pp. 11-12) is a border, for instance between countries. Parts of land that are collectively recognized as territories of countries carry various deontic powers. When moving from one country to another, there is a transition in deontic powers; different laws take effect. These transitions are practically important in many ways, so in order to aid in representational activities concerning them, we treat a transition of this kind as an object with its own features: we treat it as a border, with features such as length, location, and - in many cases - a date of creation. Borders are surrogate objects that mark where the transition in deontic powers carried by countries takes place, and as surrogate objects borders do not have deontic powers on their own. ${ }^{8}$ Yet the border is a socially constructed entity that exists in virtue of us collectively recognizing that it is there.

As borders are typically seen as prime examples of status functions (e.g. Searle, 1995, pp. 39-40), it is important to note that the same entity can serve different functions in different contexts. ${ }^{9}$ Cole emphasizes that borders serve as surrogate objects in the context of representational activities - when we talk, reason, and inquire about the transition between different parts of land. The surrogacy functions are the core functions of borders, for they account for why the entities were constructed (see Cole, 2015, p. 1108). But in the context of social practices like customs or border checks, the border entity serves a status function and involves deontic powers.

Surrogacy functions are also served by entities that do not carry deontic powers, or do so only minimally, like possible worlds, fictional characters, and-crucially for our purposes-mathematical entities such as natural numbers (Cole, 2015, p. 1110). Before examining what it means for mathematical facets of reality to be surrogate objects, two observations should be made about Cole's (2015, pp. 1110-1111) view of surrogate objects in general. First, surrogate objects are institutional entities; they owe their existence to systems of standing declarations that govern particular activities, and they are real because we collectively recognize them to be. In this regard, surrogacy functions and status functions are alike. Second, in order to serve their functions and aid us in representational activities, surrogacy objects must have properties and relations that reflect the features of the facets of reality for which they are surrogates. This requirement illustrates the key difference between surrogacy

\footnotetext{
${ }^{8}$ Similarly, Cole regards positions in organizations as surrogate objects, and thus not carriers of deontic powers, because he differentiates between the person who has a certain status in the organization and the position in the relational structure of the organization (see Cole, 2013, pp. 12-13). The president of the U.S. has deontic powers and is a clear example of someone performing a status function. On the other hand, in itself, the president's position in the U.S government does not have deontic powers; for instance, no laws can be vetoed in the situation when no one occupies the position.

9 This context-relativity applies already to the distinction between physical and status functions, as evidenced by Searle's formula " $X$ counts as $Y$ in context $C$." In the context of playing with different paper airplanes, a 10-euro bill is constructing material and serves a physical function, but in the context of buying a cup of coffee, the same object counts as money and serves a status function.
} 
and status functions: they are imposed for different purposes. Status functions are imposed to improve and enrich our social interactions, whereas surrogacy functions are imposed to facilitate our knowledge and reasoning.

\subsection{Institutional account of mathematical reality}

The central thesis of Cole's social constructivism is:

mathematical reality is the product of our collectively imposing function onto reality, where the functions in question are surrogacy functions with respect to (logically) possible systems of objects. (Cole, 2015, p. 1102)

To clarify the thesis, I take a closer look at how natural numbers are constructed in Cole's theory. ${ }^{10}$ According to Cole (2015, p. 1102), the social construction of mathematical reality originates from everyday operations like counting. First, natural numbers were introduced as tools to assist us in our dealings with small collections of concrete things. The idea is that a number, for example three, is imposed to aid in representing things like how many children someone has or how many fish we should catch to feed everyone in the family and so forth. The number three is not the same as the number of children or the number of fish, but it functions as a surrogate for the common feature that these collections have. However, this kind of construction only gets us as far as very small finite numbers and, as Cole says, "eventually, our predecessors recognized that they wished to use natural numbers to perform their RFs [representational/surrogacy functions] with respect to all (externally) possible finite collections" (Cole, 2013, p. 29, emphasis in original). The notion of logically possible systems of objects is introduced; concrete collections are of some definite finite cardinality, but it is possible-logically, not concretely-to always add to a collection, with no upper limit put on the size. To put it differently, any possible system of finite cardinalities forms an $\omega$-sequence, meaning that it has a first member, a second member, and so forth, but no last member (Cole, 2015, p. 1118). We need to be able to represent this, so we extend our system of natural numbers to serve surrogacy functions with respect to all logically possible collections, not merely the sizes of concrete collections. Doing so, we have constructed the entire sequence of natural numbers, and since we collectively recognize them, natural numbers exist as institutional entities.

To sum up, natural numbers are surrogate objects that are constructed to represent logical possibilities about finite cardinalities. Not only natural numbers, but in Cole's theory, all mathematical facets of reality are surrogates (Cole, 2015, p. 1111). They were constructed to represent various logical possibilities, and they exist because we collectively recognize that they do. Because mathematical entities are institutional, they are abstract entities in at least the minimal sense that they are not concrete, spatially located entities. Furthermore, despite being institutional entities, Cole argues that mathematical facets of reality are (1) robust, meaning that

10 This is an attempt to expand and elucidate the story told by Cole $(2013,2015)$. 
their existence is not accidental; (2) non-arbitrary because they have features that are strongly constrained by their core functions; and (3) objective in the sense of semantic objectivity. I will return to these arguments in more detail in section five, when I examine how well Cole's institutional theory succeeds as a social constructivist account of mathematics.

\subsection{Answering an objection: how is this realism?}

Let me address an obvious objection to Cole's account of mathematical reality and social constructivism in general: How can this be realism? In Cole's view, mathematical objects are surrogate objects and ontologically dependent on their being collectively recognized. This points strongly toward an antirealist ontology. Yet Cole calls his previous social constructivist view realism, albeit practice-dependent realism, and his institutional theory holds that mathematical facets of reality genuinely exist. How is this possible?

This is accomplished by uncoupling two conditions, which usually go strictly hand in hand. Typically, ontological realism concerning $X$ is a combination of two claims: (1) $X$ exists, and (2) $X$ is mind-independent (or independent of human thought, beliefs, and practices). Cole takes only the existence claim and leaves out the independence claim. His account of mathematical reality is realist in the sense that it affirms the existence of abstract mathematical entities. As such, it is a form of what Linnebo (2018) calls object realism, without being platonism. Platonism adds to object realism the claim of independence, which is often understood through an analogy between mathematical entities and physical objects: "Just as electrons and planets exist independently of us, so do numbers and sets." (Linnebo, 2018, sec. 4.1). Mathematical social constructivism rejects this analogy, along with the tendency to conflate being real with being independent that is common to platonism and the viewpoint of natural science. In its understanding of realism, mathematical social constructivism aligns more with social ontology, where the key point is that things that are practice-dependent can nevertheless be real. The problem with maintaining that realism requires independence is that it also leaves out a plethora of things that are treated as real in both sciences and everyday life. If a thing-an object, a phenomenon, a process-can only be real if it is independent of human practices, we must conclude that things like money, states, governments, thoughts, emotions, etc. are not real, and this is not something a realist-leaning social constructivist is willing to do.

Because Cole's social constructivism is a form of object realism, it stands opposed to nominalism, the view that mathematical entities do not exist. While Cole's theory of mathematical entities being surrogate objects has some commonalities with antirealist views like instrumentalism or fictionalism, a crucial reason to hold that Cole's social constructivism is indeed a form of realism is that even though mathematical entities are introduced as tools to serve representational purposes, they take on a life of their own in some sense. On one hand, after being introduced, mathematical entities are shared between mathematicians and studied as external objects. In other words: "Once created and communicated, mathematical objects are there. 
They detach from their originator and become part of human culture." (Hersh, 1997, p. 16, emphasis in original). On the other hand, mathematical entities detach from the purpose of their introduction. As Cole (2013, p. 27) says, "having introduced such domains, we became interested in them, and began to investigate them, independently of their RFs [representational/surrogacy functions]."

Importantly, a social constructivist like Cole does not attempt to reduce mathematical entities to subjective mental features or to physical things, but takes them to be entities in their own right. What is studied in mathematics is the mathematical entities as themselves, as abstract institutional entities, not the facets of reality they represent. As a consequence, the terms used in mathematical theories are not merely shorthand for something else, but they can be taken literally. This differentiates social constructivism from many forms of nominalism, such as Hartry Field's fictionalism or modal structuralism, which require a reconstruction of mathematical language to avoid ontological commitments to mathematical objects. ${ }^{11}$ In contrast, social constructivism has no problem with taking mathematical language at face value, nor with ontologically committing to mathematical entities, albeit in a different sense than platonism. Regarding ontological realism, we can then say that mathematical social constructivism is not quite realism in the typical sense but not antirealism, either. ${ }^{12}$ As it affirms the existence of mathematical entities but denies their independence of human activity, social constructivism occupies the middle ground between nominalism and platonism.

Cole's account of mathematics is not only realist in the ontological sense, but also in a semantic sense. ${ }^{13}$ Cole $(2015$, p. 1103) states: "throughout, I assume that the majority of classical mathematical statements have objective truth values." Additionally, the true mathematical statements are taken to be truths about existing entities. Cole's view is thus a moderate ${ }^{14}$ form of truth-value realism, which is the view that mathematical statements have objective, non-vacuous truth values independently of the conventions or knowledge of the mathematicians (see Linnebo, 2018; Shapiro, 1994). Assuming truth-value realism has the benefit of supporting the legitimacy of

\footnotetext{
11 The problem is that if there are no mathematical objects (and assuming standard semantics), a statement such as "there are infinitely many primes" comes out as false, which goes against mathematical practice. To resolve this discrepancy, Field adds a fictional operator to the language, which transforms the false statement into "in arithmetic, there are infinitely many primes," which is true. Modal structuralism does the same by reinterpreting mathematics in terms of modal logic and translating mathematical statements into hypothetical statements about possible structures. (See Bueno, 2020).

12 Tellingly, proponents of mathematical social constructivism locate their views on different sides of the realism-antirealism divide. Ernest (1998, p. 261), who sees mathematical entities as cultural or conceptual objects, describes social constructivism as nominalism. Reuben Hersh, who uses the term 'socialcultural-historical object' for mathematical entities, thinks they are "real as can be" (1997, p. 72). And, as emphasized, Julian Cole takes the realist side.

13 I want to thank an anonymous reviewer for prompting me to discuss this sense of realism in more detail.

14 I add the qualifier 'moderate', because rather than assuming that every mathematical statement has an objective truth value, Cole talks of the majority of statements. For instance, Cole's formulation leaves it open whether unsettled and independent questions like the continuum hypothesis have determinate truthvalues.
} 
classical methods, such as the use of classical logic or non-constructive proofs and axioms, even when platonism as a defense of the use of these methods is rejected.

One might wonder, how statements about institutional entities, which exist in virtue of our collective recognition, have truth values independently of us. But as Linnebo (2018) notes, the claim that mathematical statements have objective truth values need not be justified by appealing to the ontology of mathematical entities. Cole's truth-value realism does not rest on the ontological nature of institutional mathematical entities, but on a feature of their core surrogacy functions: because surrogacy objects reflect the facets of reality for which they are surrogates, statements about mathematical entities inherit their truth-values from statements about logically possible systems of objects. The question remains, whether appealing to the logical possibilities suffices to justify Cole's truth-value realism, but I return to this question in section five. First, I take up the question: Why defend social constructivism about mathematical reality?

\section{The promise of social constructivist ontology for mathematics}

Social constructivism about mathematics, like Cole's institutional theory, has some promise as an ontology for mathematics. In this section, I identify two merits that support the view that mathematical objects are social constructions, one from the point of view of mathematical practice and the other from the point of view of a more general ontological picture. I then offer a new argument for social constructivism that combines these two viewpoints.

\subsection{Two merits of social constructivism}

The first merit is that social constructivism can agree well with mathematical practice. Some reasons for this have already been discussed. To begin with, social constructivism as a philosophy of mathematics is not revisionist. Unlike constructive mathematics, it does not try to tell mathematicians what they should do or what methodologies to use. As I see it, the aim of social constructivism is to make sense of what mathematicians are doing when they talk about mathematical objects, whatever methods they are using. The metaphysical account of mathematical entities the view offers is compatible with different mathematical methodologies-both classical and constructive- and does not put restrictions on the choices a working mathematician can make.

Another reason is that social constructivism offers a solution to the ontological puzzle arising from practice. The view validates ontological commitments because mathematical entities genuinely exist as institutional entities, and it also validates creative postulation because mathematical entities are constructed. Social constructivism can also validate the experience of discovering unknown features of mathematical entities. This is because socially constructed entities-unlike explicit constructions-can have features that are not known or anticipated when the entities are constructed. The idea of unintended or unknown features could become clearer 
through an example of a more familiar social entity, the game of chess. It is a feature of the game that the quickest possible checkmate is the sequence of four moves called the Fool's Mate. This feature is not stated in the rules that constitute the game nor is it apparent by knowing the rules alone, but rather, it has been discovered through playing and analyzing the game. Since similar situations may occur for socially constructed mathematical entities, social constructivism can account for the sense of discovery that is part of the experience of doing mathematics.

Furthermore, case studies of actual mathematical practice lend support for the core idea of social constructivism - that mathematical entities exist in virtue of human activity yet are genuine aspects of reality - although not necessarily for the specifics of Cole's institutional theory. Carter (2004) argues based on a case study from modern mathematics, $K$-theory, that new mathematical objects grow out of mathematical practice. For Carter (2004, p. 253), the case study shows that new objects are introduced by mathematicians in order to solve problems and they are constructed from already accepted objects by using accepted construction methods. Still, Carter claims, because we can successfully speak about mathematical objects, they are entitled to some kind of existence, and she views them as genuine objects. ${ }^{15}$ Muntersbjorn (2003) proposes that mathematical objects are real but emergent phenomena, and that they are neither created nor discovered, but cultivated. She gives evidence for this view with a historical case study of the development of calculus by showing how derivatives and integrals emerged from representational practices. Based on the case study, Muntersbjorn argues that new notational devices play a vital role in the emergence of mathematical objects: "Mathematical objects do not exist before the introduction of new mathematical symbols, but only come into existence after systems of signification capable of referring to them are codified via the mathematical community." (2003, p. 173). Both case studies support the idea that mathematical entities are brought into reality by the activities of mathematicians, and this idea is also at the core of Cole's social constructivism.

However, whether mathematical practice on its own is enough to draw conclusions about the ontology of mathematics has been disputed. Some hold that it makes no difference to mathematics as it is actually practised whether mathematical entities are taken to exist or not (see e.g. Larvor, 2001; Maddy, 2011). Fortunately, agreement with mathematical practice is not the only reason to defend social constructivism about mathematics, for the view also has advantages from a more general ontological viewpoint.

The second merit of mathematical social constructivism is that it provides an ontology for mathematics that fits into an overall scientific worldview. To paraphrase Searle (2010, p. 3), the aim is to answer this question: How can we reconcile a conception of the world as described by the sciences with what we think we know

\footnotetext{
15 Carter (2004, p. 261) defines genuine objects, in contrast to fictions, as those for which the act of exhibition can be distinguished from the act of definition. The way to exhibit mathematical objects can be to represent them with empirical objects, as in the case of a triangle, or to derive them from the methods of constructions, as in the case of $K$-groups. According to Carter, neither method of exhibition is the same as giving a definition for these objects.
} 
about the subject matter of mathematics? Social constructivism does this by offering a way to understand how mathematical entities can be real without postulating Platonic realms. Any kind of independently existing, acausal, and non-spatiotemporal mathematical world is a significant problem for a worldview that is informed by the sciences and is, broadly speaking, naturalistic. But claiming that mathematical entities are real in the same way that legal borders and money are real does not conflict with a scientific picture of the world, at least not anywhere close to the same degree that a platonist reality does.

What I mean by the scientific worldview is a kind of non-reductionist naturalism, the gist of which can be characterized by two claims ${ }^{16}$ : First, the natural world we live in includes all kinds of phenomena from quarks to governments, and there are no separate realms of existence. Different sciences, from physics to biology and to social sciences study different aspects of the same reality. Second, more complex aspects of reality, including mental and social reality, are in some ways dependent on more basic aspects of reality and ultimately on physical entities. Note that, as the descriptor 'non-reductionist' indicates, the view holds that dependent entities can be genuinely real. The problem that platonism presents for this kind of naturalistic worldview is created by the claim of independent existence rather than by the abstractness of mathematical entities. Hence, social constructivism poses no comparable problem to naturalism. As Linnebo (2018) observes, many physicalists would accept non-physical objects such as corporations, laws, and poems, provided that they are suitably dependent on physical reality.

I take it that all kinds of human activities and culture, including the important and fruitful activity of doing mathematics, are continuations of simpler, evolutionarily developed skills and practices. Hence, these activities - and the products of these activities - belong to the same natural world inhabited by planets and trees and elementary particles. This is in line with Searle's claim that his account of institutional reality is utterly naturalistic since he sees "the human ability to create money, property, government, and marriage as an extension of more basic biological phenomena such as the ability of human beings to engage in cooperative behavior, and their innate capacity for linguistic symbolism" (Smith \& Searle, 2003, p. 300). The reality of social entities is continuous with the reality of physical entities, and since the situation is the same with socially constructed mathematical things, they are compatible with what the sciences tell us about reality.

\subsection{The argument from compatibility}

These two merits can be combined into a single argument for social constructivism. This argument differs from two arguments given by Cole $(2008,2009)$ and reconstructed by Dieterle (2010) in her critique of Cole's theory. I will first briefly describe and comment on these arguments and then present my own argument.

\footnotetext{
16 These claims are similar to the two conditions of adequacy Searle sets for his account of social reality (2010, pp. 3-4).
} 
The first is the Argument from Phenomenology, the same argument I called the ontological puzzle which, according to Dieterle (2010, p. 321), functions as motivation for adopting social constructivism but not as a direct argument in support of the position. The second is the Argument from Superfluousness, which aims to show that social constructivism is preferable to platonism (Dieterle, 2010, pp. 316-317). The gist of the argument is that platonism is explanatorily and justificationally superfluous; because of the problem of acausal entities influencing us, platonistic entities cannot perform some of the required explanatory work, and the remaining work can also be done by socially constructed mathematical entities. Platonistic entities are thus unnecessary and fall under Occam's razor. Dieterle is skeptical of this argument for several reasons. First, she doubts that socially constructed entities are able to do the explanatory work required of platonistic entities, namely accounting for the characteristic features of mathematics. Second, she is not convinced that the influence challenge does not also apply to Cole's theory since, in his view, mathematical entities are abstract. And third, she is suspicious of the use of Occam's razor in this case because it may be similarly applied to socially constructed entities.

Let me quickly respond to Dieterle's critiques. Concerning the first, I agree that a social constructivist view needs to account for characteristic features of mathematics, and I will turn to this question in the next section. Regarding the influence challenges, I share Cole's view that they do not present a significant problem for social constructivism since socially constructed mathematical entities can influence us through the practices that constitute them (e.g. Cole, 2008, p. 124). The main difficulty of gaining epistemological access to platonistic entities seems to be due to their independence, not their abstractness. This is supported by the observation that similar questions do not commonly arise in the case of presumably abstract entities that are human-created, such as symphonies, novels, or constitutions. And finally, like Dieterle, I do not find the use of Occam's razor fully convincing in the case of mathematics. In particular, I doubt whether the razor is the best tool to decide between different realist views about mathematical ontology. If ontological parsimony is taken as an important guiding principle for ontology, granting the vast domains of modern mathematics any kind of existence seems questionable.

Instead of focusing on ontological parsimony, I favor other guiding principles for ontology: (1) compatibility with experience, which in the case of mathematics means actual mathematical practice, and (2) compatibility with the results of empirical sciences, understood broadly and not restricted to natural sciences or physics. ${ }^{17}$ The two principles mirror the merits identified above and function as premises for my argument for social constructivism in mathematics, which I dub the Argument from Compatibility. The new argument incorporates the crux of the Argument from Phenomenology and, in my view, gives a more convincing reason to prefer social

\footnotetext{
17 Both principles are naturalistic in some sense. The first aligns with the basic idea of mathematical naturalism, defended by e.g. Penelope Maddy, by requiring that a philosophical account of mathematics should not conflict with mathematical practice. The second principle rests on a moderate form of naturalism that combines core notions from both ontological and methodological aspects of naturalism, namely that all entities are in some sense natural and the best ways to investigate the nature of reality are scientific methods.
} 
constructivism over platonism than the Argument from Superfluousness. Consequently, I claim that the Argument from Compatibility makes a stronger case for social constructivism than the two arguments given by Cole. The outline of the argument is the following:

(1) The principle of compatibility with practice: Any philosophy of mathematics should agree with the actual practice of mathematics.

(2) The principle of compatibility with science: Any ontology should agree with what the empirical sciences (broadly conceived) tell us about the nature of reality.

(3) The practice of mathematics has aspects that are explained by the view that there are mathematical entities: reference to entities, existential claims, sense of discovering objective features.

(4) Platonism and social constructivism account for (3). Other ontological views (nominalism, empiricism, etc.) do not, violating (1).

(5) Platonism postulates an independently existing realm of mathematical entities, that is acausal and non-spatiotemporal. This violates (2).

(6) Conclusion: social constructivism is preferable to other ontological views.

The difficult step in this argument is step (4). Specifically, the argument hinges on whether social constructivism can account for the characteristic features of mathematics. I will now turn to examining how Cole's institutional account fares in this regard. Reference to entities and existential claims are taken care of by the claim that mathematical entities exist as institutional entities. Objectivity is the challenging feature for social constructivism, and it is not the only one.

\section{Challenges: objectivity and applicability}

There are two major challenges facing mathematical social constructivism due to mathematics having characteristic features that other socially constructed facets of reality do not. As pointed out in the previous section, the first one is objectivity. Mathematics is widely regarded as the epitome of objective knowledge, and compared to typical socially constructed entities, mathematical entities are (relatively) non-arbitrary. The second feature is applicability. As is well known, applying mathematics in the natural sciences is very effective, even unreasonably so. ${ }^{18}$ Because this is the case, mathematical reality appears to be connected to the features of the physical world in a way that other facets of social reality are not.

18 To borrow the famous titular phrase from Wigner (1960). 
If mathematical social constructivism is to be a viable philosophy of mathematics, the challenge is to explain these two characteristic features. ${ }^{19}$ In other words, we need to explain how and why mathematical entities differ from entities like virtual currencies or fictional characters. According to Cole (2015, p. 1110), both mathematical entities and fictional characters are surrogate objects and are constructed by the same mechanism. But fictional characters are highly arbitrary and not at all useful in explanations of physical phenomena, so there are significant differences in need of explanation.

\subsection{How Cole's institutional theory explains objectivity and applicability}

Cole's explanation for the objectivity of mathematics relies on the distinction between ontological and semantic objectivity. ${ }^{20}$ Ontological objectivity has to do with the existence of entities; those entities that exist mind-independently are ontologically objective. Semantic objectivity has to do with claims and propositional content; objective claims are those that have a truth value independently of the attitudes of those who assess them. Note that the semantic objectivity of statements is an important part of truth-value realism, although typically truth-value realism makes further and stronger claims.

According to Cole's theory, mathematical entities are dependent on collective recognition, so they are not ontologically objective. However, Cole (2015, p. 1122) argues that mathematical claims are semantically objective. But as Dieterle (2010, p. 326) argues, this kind of objectivity is not yet enough because claims about other socially constructed entities are semantically objective too, and mathematics should be objective in a much stronger sense than, for example, claims about the features of gender constructs. ${ }^{21}$ To explain this discrepancy, Cole (2015, pp. 1121-1122) argues that the truth values of some semantically objective contents are constrained

19 Many also see timelessness and necessity as characteristic features of mathematics that need to be accounted for. I do not consider them as essential for an account of mathematics as the other two features I identify. The reason being that, if timelessness and necessity are understood as mathematical truths being true at every time and in every possible world, requiring mathematics to be timeless and necessary is inherently at odds with the humanist view that mathematics is a historically developed product of human activity and ingenuity. This incompatibility is well illustrated by Dieterle (2010, p. 318, n. 14): "when we say mathematical truths are timeless, we mean that they were true before there were rational minds and will remain true even if, at some point in the future, there are no rational minds. It is difficult (if not impossible) to make sense of this if such truths depend on rational activities of humans." The claim of the humanistically minded philosopher of mathematics is precisely that this does not make sense and mathematics is not in fact timeless. However, as an anonymous reviewer points out, this understanding is better called eternal than timeless, and unlike eternality, timelessness or atemporality could be compatible with the humanist view. Accordingly, Cole argues that institutional mathematical entities are amodal and atemporal existents, rather than necessary and eternal. This is because, in order to best serve their core functions, no temporal or modal restrictions are placed on them (Cole, 2015, p. 1111). The idea is that, after they have been introduced, the surrogacy functions mathematical entities serve can be imposed onto past reality retroactively, or onto the reality of any time or any possible world.

20 The distinction is based on Searle's (2010, p. 18) similar distinction of different senses of objectivity.

21 As Dieterle points out, the aim of social constructivism about gender is precisely to show that statements like "women are more nurturing than men" are not objective. 
to be what they are by the features of ontologically objective facets of reality, and other contents are unconstrained. Correspondingly, some socially constructed entities have non-arbitrary features and others only highly arbitrary ones, depending on how strongly they are constrained by their core functions and, if their functions are representational, the features of ontologically objective reality.

For example, the features of gender constructs and the true claims about them are not constrained by ontologically objective reality and are therefore liable to change. This is in contrast with mathematics: Cole (2015) argues that mathematical entities have non-arbitrary features and that mathematical content has semantic objectivity that is largely or entirely constrained because it represents features of ontologically objective facets of reality. For example, the statement " $7+5=12$ " has the same truth value as "when collections of seven and five are combined, the result is a collection of twelve." This claim directly represents how concrete collections work, which is ontologically objective (Cole, 2015, p. 1122). Thus, the explanation for the objective nature of mathematics is that mathematical constructs are constrained by ontologically objective parts of reality.

What about an explanation for the applicability of mathematics in natural sciences? Cole does not provide one, but the explanation that can be given for this feature in Cole's theory relies on the notion that mathematical entities are surrogates for other facets of reality. According to Cole (2015, pp. 1116-1119), surrogate objects must have properties that reflect the properties of the facets of reality for which they serve as surrogates. If mathematical entities are to serve their surrogacy functions well, they must reflect the features of the physical world. This is well illustrated by the case of natural numbers and basic arithmetic; because natural numbers represent quite directly how physical collections work, it is clear why they can be used effectively in scientific and other explanations of physical phenomena.

\subsection{Why Cole's theory falls short of meeting the challenges}

Cole's theory makes a decent attempt at giving explanations for objectivity and applicability, but I argue that it ultimately falls short of the mark. The explanations run into problems caused by the three-level theoretical model Cole sets up and the ambiguity of the crucial notion of possible systems of objects. Additionally, due to the Searlean framework, Cole's institutional account fails to sufficiently address the different constraining factors that are relevant to explaining the particularities of mathematical social construction.

\subsubsection{Problems caused by the three-level theoretical model}

The way Cole (2015) explains the construction of mathematical reality hinges on a theoretical model, which, while not explicitly described and defended by Cole, becomes apparent on a close look at the theory. The model has three levels (see 
Fig. 1). ${ }^{22}$ The first level consists of independently existing reality and features of the physical world, for example concrete collections. Logically possible systems of objects form the second level. On the third level are the institutional mathematical entities that serve as surrogates for the second-level entities, as the central thesis of Cole's social constructivism states. The first-level entities and features are straightforward, and Cole gives a detailed, Searle-inspired account of the ontology of the third-level entities. But adding the level of possible systems of objects between these and failing to give a clear account of their ontology causes the theory to fail to adequately explain the objectivity and applicability of mathematics.

Both explanations hinge on the notion of logically possible systems of objects because they are what constrains the objectivity of mathematics, and if there is a connection between mathematical reality and the physical world, it goes through the logical possibilities. Since the third-level mathematical entities are surrogate objects, they have the same degree of constraint as the second-level possibilities. This means that Cole's truth-value realism depends on statements about logically possible objects being semantically objective in a strongly constrained way. Consequently, in order to substantiate the claim that mathematical statements have objective truth values, Cole (2015, p. 1103) has to assume that "there are ontologically objective facts about what systems of objects are logically possible" and that our assessments of the relevant logical possibilities are made correct by features of independent reality. The problem is that Cole does not justify this assumption, nor does he explain how ontologically objective reality actually fixes what the possibilities are.

The problem occurs especially in the case of entities that do not directly represent concrete things. The explanations given for the characteristic features of mathematics work in the case of natural numbers because their features are strongly constrained by a clear connection between the facts of ontologically objective reality and the constructed mathematical entities. For natural numbers, this connection "can be expressed by an abstraction principle" (Cole, 2013, p. 33). But Cole's theory has trouble accounting for objectivity and applicability in more advanced mathematics since it is not clear at all how entities like symmetry groups or $n$-dimensional Euclidian spaces—or more precisely, the logical possibilities for which they are surrogates-are connected to and constrained by ontologically objective features of reality. For example, Cole says that "we collectively recognize the complex numbers to serve surrogacy functions with respect to all (logically) possible norm division algebras over the reals that have dimension 2" (2015, p. 1111). How are "possible norm division algebras" connected to the first-level features of the physical world? The same kind of straightforward abstraction that works for natural numbers is not an option because this is not a case of representing concrete things. Still, a connection of some kind is presumably required since Cole assumes that some feature of independent reality fixes what systems of objects are logically possible. The

\footnotetext{
${ }^{22}$ In Cole (2013), the three levels are less explicit but are still present in the account. Cole (2013, p. 30) describes mathematical domains as serving RFs (i.e. surrogacy functions) with respect to possibilities of a relevant type.
} 


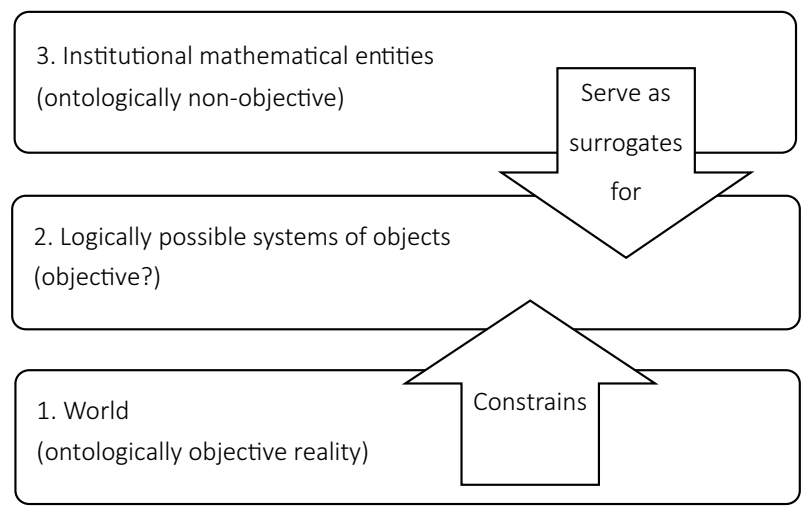

Fig. 1 The three-level model of the construction of mathematical reality

lack of an explanation for these kinds of connections is a shortcoming of the theory since many entities of advanced mathematics do, in fact, find applications in physical theories, some even in unexpected ways. For example, matrices are successfully applied to quantum physics (see Wigner, 1960), and the theorems of group theory can be used to predict the behavior of subatomic particles (see Maddy, 2011, p. 95).

Further complications arise from the fact that the example of complex numbers mentions the reals, which themselves are surrogate objects in Cole's theory. One way to understand the situation is to take the imposing of surrogacy functions as iterative. That is, new mathematical entities (complex numbers) would be surrogates for the features of previously constructed surrogate objects (the field of real numbers). This seems a natural interpretation since mathematics builds on previous mathematics. In fact, Cole (2013, p. 27) makes the same point and states that is useful to think that mathematical reality has been constructed in layers. However, the iterative interpretation exacerbates the problem of explaining the objectivity of mathematics. The objectivity of upper-layer mathematics is constrained by the features of the lower layer, which consists of surrogate objects. But because these are not ontologically objective entities, how can facts about what is possible for them be ontologically objective, as the theory requires?

This question highlights the issue of "passing the buck" underlying Cole's theory; the question of whether mathematics is about something ontologically objective or not is just shifted from concerning the third-level mathematical entities to being about the second-level logical possibilities. Either we have to claim that the relevant logical possibilities are as they are independently of us, or we have to accept that the logically possible systems are partly or entirely constructed by us and are thus not ontologically objective. Taking the first option, as Cole seems to, amounts to essentially endorsing platonism about logical possibilities. This leads to an uneasy combination of positions: holding that entities like real and complex numbers are constructed by us yet what is logically possible for these entities is independent of us. On the other hand, taking the second option removes the basis for Cole's explanations for objectivity and applicability. If the logically possible systems of objects 
are constructed by us in a partly or largely unconstrained way, the objectivity of mathematics would be severely weakened, and the connection to the physical world, which accounts for applicability, would be severed.

In sum, Cole's three-level model creates problems that cause his institutional theory to fall short of meeting the challenges facing social constructivism. The theory either collapses into platonism regarding possible systems of objects or fails to account for characteristic features of mathematics.

\subsubsection{The Searlean framework behind the shortcomings}

The examination of objectivity and applicability shows that the constraints placed on the construction of mathematical entities do the bulk of the work in accounting for the characteristic features of mathematics in Cole's institutional theory. As I see it, appealing to the constraints attempts to answer the question: What makes mathematicians collectively recognize and bring into existence entities that are distinctly mathematical, meaning that they can be applicable and facts about them are objective? Cole's answer is that in order to serve their core functions as surrogate objects, the features of mathematical entities are constrained to a high degree by the features of the logically possible systems they represent. But as the problems caused by the three-level model show, relying only on the constraints placed by the core functions of mathematical entities does not give a sufficient answer to this question.

The significant role played by the constraints suggests that the problems Cole's theory has explaining the characteristic features of mathematics could be resolved by elaborating on other factors constraining social construction of mathematical entities. This could be approached in two ways: First, by considering what else constrains the features of mathematical entities, aside from the other aspects of reality they represent, and second, by looking at what convinces mathematicians to accept certain entities. In social constructivism, these aspects are tied together: what mathematical entities exist depends on the collective recognition of mathematicians, but the entities that mathematicians come to recognize typically are the ones whose features are strongly constrained. Regarding the first aspect, the features of mathematical entities can be constrained not just by what they represent but what they allow. Natural candidates for these kinds of constraining factors include an ability to solve problems or settle open questions, ability to expand the domains or open new areas of study, and fruitfulness in application either in science or in other areas of mathematics. Regarding the second aspect, the most important factors are proofs; the best way to convince mathematicians to accept an entity is to give a proof of its existence using already accepted entities and principles. It should be noted that these other constraining factors, like having a proof, are not strictly speaking necessary conditions for a certain mathematical entity to be constructed. Rather, the presence of constraining factors corresponds to the extent to which the entity in question has non-arbitrary and applicable features and to how objective our knowledge of the entity is.

Consequently, paying more attention to these factors could be of considerable help to a social constructivist in the task of accounting for the characteristic features of mathematics. Yet, in his institutional account of mathematics, Cole remains 
mostly silent on other possible constraining factors than the representational ones. I propose that this is due to the Searlean framework Cole bases his theory on. Focusing primarily on representations and failing to sufficiently address other constraining factors seems to be inherited from Searle's theory.

Searle's (2010) central claim is that all institutional reality is created and maintained in existence by the mechanism of status function declarations and collective recognition. But, as Tsohatzidis (2010) observes, some institutional facts cannot be created just by making declarations: I cannot go on strike just by saying "I go on strike" or-as also Searle (1995, p. 55) admits-I cannot make a touchdown just by saying "I'm now making a touchdown." Factors other than declarations are also involved in the creation of these institutional facts. However, they easily go overlooked in the Searlean framework, since Searle's central claim implies that declaration and collective recognition alone are enough to bring something into existence.

The same problem carries over to Cole's institutional account of mathematics and leaves it vulnerable to an objection that can be made against a view that mathematical entities are socially constructed: "Surely, the existence and the features of mathematical entities cannot be just a matter of what leading mathematicians decide in a conference." The objection rests on the fact that this is not how mathematics develops in practice. Yet the Searlean framework leads us to believe that this would be sufficient; mathematicians could create a new entity just by declaring and collectively recognizing that it exists and has certain features, and nothing more would be needed. As it overlooks other factors in play, the institutional account has difficulty in properly responding to the objection.

More importantly, the Searlean framework contributes to the shortcomings of Cole's explanations for objectivity and applicability by steering the focus away from other kinds of constraining factors that are relevant for an account of mathematics, and detrimentally limiting the theory's ability to explain the particularities of mathematical social construction. This is not to say that the institutional approach is utterly unable of overcoming the shortcomings by supplementing the theory, but it seems that the theoretical tools needed to explain the characteristic features of mathematics are not the ones provided by Searle's theory. The shortcomings of the institutional account of mathematics, along with the lack of tools the Searlean framework offers to overcome them, give reason to suspect that the Searlean framework is not an optimal social ontology for the purposes of defending mathematical social constructivism.

\section{Conclusion}

To conclude, I have proposed that a view that sees mathematical entities as socially constructed has some promise as an ontology of mathematics. Social constructivism offers a way to understand how mathematical entities can be real without postulating any Platonic realms and conflicting with a scientific picture of reality. Furthermore, the view can agree well with mathematical practice: it is not revisionist, and it gives 
a solution to the ontological puzzle by validating both existential claims and creative postulation done in the course of doing mathematics.

But for social constructivism to be a viable ontology of mathematics, it needs to overcome the challenge of explaining the characteristic features of mathematics. I have argued that the institutional theory of mathematical reality defended by Julian Cole fails to sufficiently account for the objectivity and applicability of mathematics. The explanations for these features run into problems caused by an underlying three-level theoretical model and ambiguity of the crucial notion of possible systems of objects. Moreover, basing the theory on the Searlean framework results in overlooking other relevant factors constraining mathematical social construction than representational ones, which limits the theory's ability to explain the particularities of mathematical social construction.

As a result, Cole's institutional account fails to deliver on the promise of social constructivism about mathematics. Because the theory does not sufficiently account for characteristic features of mathematics, the Argument from Compatibility I presented in support of mathematical social constructivism does not fully apply to Cole's institutional version. The shortcomings of Cole's theory give reason to suspect that the Searlean framework he works with is not an optimal social ontology for the purposes of mathematical social constructivism.

Acknowledgements I want to thank Mirja Hartimo and Arto Laitinen for their invaluable help during the process of writing this paper, two anonymous reviewers as well as Jani Hakkarainen for their helpful and encouraging comments on earlier versions of this paper, and The Emil Aaltonen Foundation for funding this research.

Funding This research was funded by The Emil Aaltonen Foundation (Grant 200204 N).

\section{Declarations}

Conflict of interest The author has no conflicts of interest to declare.

Open Access This article is licensed under a Creative Commons Attribution 4.0 International License, which permits use, sharing, adaptation, distribution and reproduction in any medium or format, as long as you give appropriate credit to the original author(s) and the source, provide a link to the Creative Commons licence, and indicate if changes were made. The images or other third party material in this article are included in the article's Creative Commons licence, unless indicated otherwise in a credit line to the material. If material is not included in the article's Creative Commons licence and your intended use is not permitted by statutory regulation or exceeds the permitted use, you will need to obtain permission directly from the copyright holder. To view a copy of this licence, visit http://creativecommons.org/licen ses/by/4.0/.

\section{References}

Balaguer, M. (1995). A platonist epistemology. Synthese, 103(3), 303-325. https://doi.org/10.1007/ BF01089731

Bridges, D., \& Palmgren, E. (2018). Constructive mathematics. In Zalta, E. N. (Ed.), The Stanford encyclopedia of philosophy (Summer 2018 Edition). https://plato.stanford.edu/archives/sum2018/entries/ mathematics-constructive/ 
Bueno, O. (2020). Nominalism in the philosophy of mathematics. In Zalta, E. N. (Ed.), The Stanford encyclopedia of philosophy (Spring 2020 Edition). https://plato.stanford.edu/archives/spr2020/entri es/nominalism-mathematics/

Carter, J. (2004). Ontology and mathematical practice. Philosophia Mathematica, 12(3), 244-267. https://doi.org/10.1093/philmat/12.3.244

Cole, J. C. (2008). Mathematical domains: Social constructs? In B. Gold \& R. Simons (Eds.), Proof and other dilemmas: Mathematics and philosophy (pp. 109-128). Mathematics Association of America.

Cole, J. C. (2009). Creativity, freedom, and authority: A new perspective on the metaphysics of mathematics. Australasian Journal of Philosophy, 87(4), 589-608. https://doi.org/10.1080/0004840080 2598629

Cole, J. (2013). Towards an institutional account of the objectivity, necessity, and atemporality of mathematics. Philosophia Mathematica, 21(1), 9-36. https://doi.org/10.1093/philmat/nks019

Cole, J. C. (2015). Social construction, mathematics, and the collective imposition of function onto reality. Erkenntnis, 80(6), 1101-1124. https://doi.org/10.1007/s10670-014-9708-8

Dieterle, J. (2010). Social construction in the philosophy of mathematics: A critical evaluation of Julian Cole's theory. Philosophia Mathematica, 3(18), 311-328. https://doi.org/10.1093/philmat/nkq007

Ernest, P. (1998). Social constructivism as a philosophy of mathematics. State University of New York Press.

Haslanger, S. (1995). Ontology and social construction. Philosophical Topics, 23(2), 95-125. https://doi. org/10.5840/philtopics 19952324

Hersh, R. (1997). What is mathematics, really? Oxford University Press.

Iemhoff, R. (2019). Intuitionism in the philosophy of mathematics. In Zalta, E. N. (Ed.), The Stanford encyclopedia of philosophy (Winter 2019 Edition). https://plato.stanford.edu/archives/win2019/entri es/intuitionism/

Larvor, B. (2001). What is dialectical philosophy of mathematics? Philosophia Mathematica, 9(2), 212229. https://doi.org/10.1093/philmat/9.2.212

Linnebo, Ø. (2018). Platonism in the philosophy of mathematics. In Zalta, E. N. (Ed.), The Stanford encyclopedia of philosophy (Spring 2018 Edition). https://plato.stanford.edu/archives/spr2018/entri es/platonism-mathematics/

Maddy, P. (2011). Defending the axioms: On the philosophical foundations of set theory. Oxford University Press.

Muntersbjorn, M. M. (2003). Representational innovation and mathematical ontology. Synthese, 134, 159-180. https://doi.org/10.1023/A:1022139715092

Nutting, E. S. (2020). Benacerraf, Field, and the agreement of mathematicians. Synthese, 197, 20952110. https://doi.org/10.1007/s11229-018-1785-9

Searle, J. (1995). The construction of social reality. Free Press.

Searle, J. (2010). Making the social world: The structure of human civilization. Oxford University Press.

Shapiro, S. (1994). Mathematics and philosophy of mathematics. Philosophia Mathematica, 2(2), 148160. https://doi.org/10.1093/philmat/2.2.148

Smith, B., \& Searle, J. (2003). The construction of social reality: An exchange. American Journal of Economics and Sociology, 62(2), 285-309.

Tsohatzidis, S. L. (2010). Review of the book Making the social world: The structure of human civilization, by J. R. Searle. Notre Dame Philosophical Reviews (Vol. 2010, No. 9).

Wigner, E. (1960). The unreasonable effectiveness of mathematics in the natural sciences. Communications in Pure and Applied Mathematics, 13, 1-14.

Publisher's Note Springer Nature remains neutral with regard to jurisdictional claims in published maps and institutional affiliations. 